\title{
Job stress in Physiotherapy Teachers during COVID-19 Pandemic: A Survey
}

\section{Ratnaprabha Chudiwal *1, Neeraj Kumar ${ }^{2}$.}

${ }^{* 1}$ Intern, Dr. A. P. J. Abdul Kalam College of Physiotherapy, Pravara Institute of Medical Sciences (Deemed to be University), Loni, Rahata, Maharashtra, India.

${ }^{2}$ Professor, Dr. A.P.J. Abdul Kalam College of physiotherapy, Pravara Institute of Medical Sciences, Loni, Rahata, Maharashtra, India.

\section{ABSTRACT}

Background: Stress can affect a person in every day of life, in work, home etc. all the jobs can cause stress in varying degree. Related to work, such as teaching and jobs can cause more stress. Teacher stress has been defined as the experience by a teacher of negative, unpleasant three emotions such as the tension, anger, and depression as a result of some aspect of their work as a teacher.

Methodology: A simple random sampling of 500 participants were included all over the India, from which 211 participants responded through google forms that were created and distributed through various social media platforms. Participants were screened according to inclusion and exclusion criteria and hence 197 participants were in total included in the study. The selected participants were asked to fill the Teacher's Stress inventory scale. Data analysis which included summarizing the collected data, analytical and logical reasoning was done.

Result: Using 5 point -Likert scale, the average of 1.0-2 was $6 \%$, the average derived $2.1-3$ was $45 \%$, similar result was obtained for the range between 3.1-4, whereas for the average $4.1-5$ only $4 \%$ was observed. On comparing the cumulative results amongst males and females along with its average of 3.14 and 3.08 respectively, no significant difference was observed, since the t-test value was 0.5295 . The standard deviation seen was \pm 0.64 and \pm 0.48 in males and females respectively.

Conclusion: After the application of Teacher Stress Inventory- Revised Scale amongst Indian physiotherapist teachers, this study concluded that on an average, the teachers experience stress quite often amid COVID-19 Pandemic. Although there wasn't any significant gender wise difference.

KEY WORDS: Job stress, Physiotherapy Teachers, COVID-19 Pandemic.

Address for correspondence: Ratnaprabha Chudiwal, BPT, Intern, Dr. A.P.J. Abdul Kalam College of Physiotherapy, Loni, Maharashtra 413736, India. E-Mail: sweetychudiwal@gmail.com
Access this Article online
Journal Information

Quick Response code

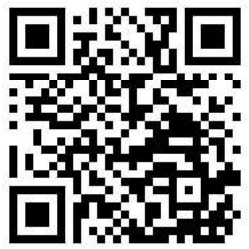

DOI: $10.16965 /$ ijpr.2021.139
International Journal of Physiotherapy and Research ISSN (E) 2321-1822 | ISSN (P) 2321-8975 https://www.ijmhr.org/ijpr.html

DOI-Prefix: https://dx.doi.org/10.16965/ijpr

\section{Article Information}

Received: 07 May 2021

Peer Review: 09 May 2021

Revised: None
Accepted: 14 Jun 2021

Published (O): 11 Jul 2021

Published (P): 11 Aug 2021

\section{INTRODUCTION}

Stress is the experience of perceived threat such as real or imaginary to the one mental and physical or spiritual wellbeing that results in series of physiological responses and adaptations [1].

It is the physical and emotional response to situation and it is perceived as frightening, confusing, exciting and tiring. It not only gets precipitated by external demand, as well as from within by our hopes, fear, expectation and the belief [2].

Stress can affect a person in every day of life, in work, home etc. all the jobs can cause stress in varying degree. Related to work, such as teaching and jobs can cause more stress. Such 
as helping profession such as teaching are generally more stressful than any other profession. ${ }^{3}$ Teacher stress is defined as the experience by a teacher of negative, unpleasant three emotions such as the tension, anger, and depression as a result of some aspect of their work as a teacher. Source of stress- Stress can be positive or negative. Positive changes like marriage, getting a new and better job, winning a match, good result or becoming a parent prove to be stressful due to increased pressure and responsibilities. which are associated with positive feeling of pleasure, confidence, excitement, happiness, love and joy, they actually increase our resistance to stress [2]. Previous Studies usually describe stress process in terms of negative emotion. ${ }^{4}$ However, evidence now states that positive emotions co-occur with negative emotion during intense stressful situation [4].

Today teachers are under the great deal of stress [5]. The Stress effect are not harmful for the only teachers, it can be harmful for the student and the learning environment also. ${ }^{5}$ teachers also experience stress as a result of the threats of physical abuse and verbal abuse and work refusal by the university students, dealing with consequences such as abuse or neglect of students, and dealing with aggressive and abusive parents [5]. There are scales to measure work responsibility but they do not measure the current ongoing conditions of overwork or job pressure also it does not include ongoing problems like unsatisfactory living condition, chronic financial pressure, Long term Health Problem and many more [6]. Teacher has too much responsibility such as upgrading the professional knowledge and motivating the students also planning the class activities and providing knowledge and skills to the students and maintaining discipline in the class and also keeping the parents informed about the child progress.

Today's fast and busy life has made the teacher's job very stressful in physically and mentally and it is very challenging for them. The major causes of stress among the teachers are due to excessive working hours in the school/ university, excessive workload, rising class size in university, changes to assessment and testing requirement, workplace bullying, poor management in the university, risk of violence from pupils, lack of job security, lack of control over the job [8]. Effect of stress on teachers include -

- Physiological manifestations such like increasing frequency of headache hypertension, tightening of muscle, fatigue and depleted energy reserves.

- Psychological/emotional manifestations including general uneasiness, depression, anxiety, nervousness, fear and frustration and loss of confidence.

- Behavioral manifestations including appetite disorder, excessive smoking and alcohol and/ or drug abuse, procrastination, withdrawal from teaching, impatience with others and low productivity [9].

The COVID-19 pandemic came out at the start of 2019, with wide range of people with working lives, this of course include teacher, with many having to quickly develop online materials and teach their pupils constantly. The period during lockdown was also a period of great uncertainty for schools/ university and teachers. some people were left wondering when exactly they can return to physically teaching in the classroom, and whether it was safe to do so.it was occurring while loved ones were getting sick and their own children were home from school that can causes stress [10]. Online learning has been gaining ground and communication technologies which become very stressful for maintaining the work in continuity for not only in the school/university but also in the all fields of the work [11].

This study will be attempting to quantify the level of stress using a teacher stress inventory questionnaire adopted from Arikewuyo (2004). This questionnaire was used by Paula Harlow in 2008 to explore the relationships between stress, coping, job satisfaction, and experience in teachers. The study mainly focused on the relationship between stress and other variables such as job Results indicated a prominent relationship between stress and job satisfaction [5]. 


\section{MATERIALS AND METHODS}

The aim of the study was the covid-19 pandemic, teachers have an increased amount of workload as they have to teach through the virtual platform. This in turn, may increases their level of stress and anxiety. This study will benefit the potential participants by making them more aware about their own individual levels of stress. This will help them act positively and hopefully direct them to manage their respective level of stress. This study was conducted in virtual platform through google form.

Google forms were created and distributed through various social media platforms. There were four sections, the first section was informed consent which was provided to the participants. The second section consisted of demographic details including name, age, gender, year of experience, teaching or non-teaching individuals. Based on these questions the participants were selected in the study. This was the third step determining the participants as per the inclusion and exclusion criteria. Inclusion criteria was All physiotherapy teachers, Male and female teachers, those who are willingly ready to participate in the study. Exclusion criteria was- Physiotherapy teachers who is taking psychotherapy, Non- teaching / clinical physiotherapist. Participants were auto-selected as per response. Then the Teacher's Stress inventory scale was filled by the participants. This was the final step. The scale involved questions which were scored accordingly: $1=$ never, $2=$ rare, $3=$ sometimes, $4=$ often, and 5 always. Scale involves 36 questions. Data was collected through the forms. The total sample size was 211 participants who filled the forms. Among them 14 participants were excluded in the study. Objective of the study was to compare level of stress in both male and female physiotherapy teachers, to differentiate the level of stress experience wise.

Conclusion of the study was concluded according to the outcome in the Teacher's Stress Inventory scale. The entire data was analysed via percentage and statistical presentation. Ttest was applied to compare the gender wise stress level. we also compare the experience wise stress.

\section{RESULTS}

The study was an online based survey, which was regulated amongst physiotherapy teachers across India, for which the study received 197 responses. These responses help me to determine the result which was needed to be achieved. The outcome measure was determined according to the choices filled up by the subjects.

These are the readings which has determine the average of the responses. The average of 1.0-2 was $6 \%$, the average derived 2.1-3 was $45 \%$, similar result was obtained for the range between 3.1-4, whereas for the average 4.1-5 only $4 \%$ was observed. These observations are also shown in graph 1.

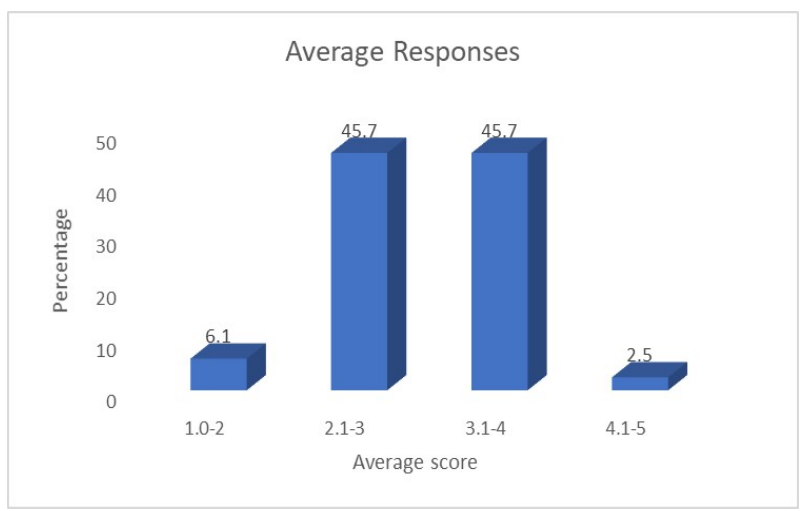

Graph 1: Percentage of average score given by the population.

On comparing the cumulative results amongst males and females along with its average of 3.14 and 3.08 respectively, no significant difference was observed, since the t-test value was 0.5295 . The standard deviation seen was \pm 0.64 and \pm 0.48 in males and females respectively. This has been shown in the graph 2 .

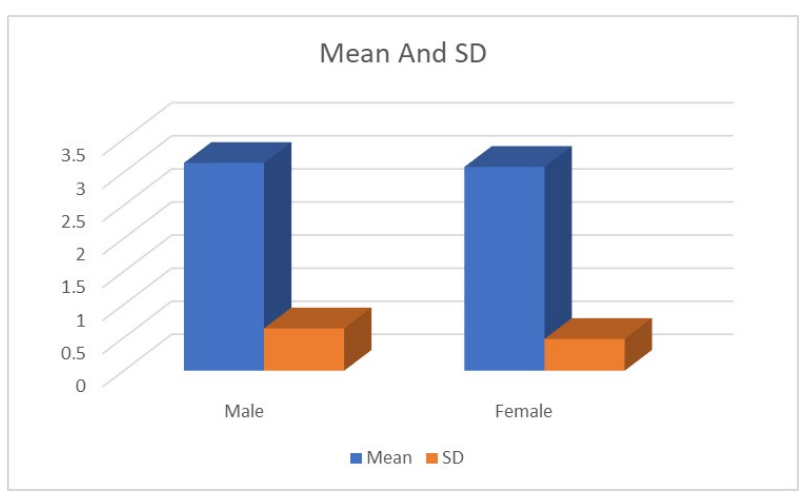

Graph 2: Mean and standard deviation of male and female teachers having stress. 
Females responded more than males. Considering the experience of the subjects, a varied data was observed. The responses obtained from subjects under 12 months of experience were 31 out of which females responded comparatively more than males. The subjects with experience lying between 13 to 60 months had a markedly higher response from females which was almost three times higher than the males. Equal males and females responded among the individuals with the experience of 61 to 108 months. Females' physiotherapist teachers' response was twice higher than males' having the experience of 109 months to 156 months. Quite less response was received from the individuals with experience higher than 157 months cumulatively. This is shown in Table 1.

Table 1: Compared experience of teaching, among male and female teachers.

\begin{tabular}{ccc}
\hline $\begin{array}{c}\text { Experience } \\
\text { (In Months) }\end{array}$ & $\begin{array}{c}\text { Male } \\
\text { Responses }\end{array}$ & $\begin{array}{c}\text { Female } \\
\text { Responses }\end{array}$ \\
\hline$\leq 12$ & 3 & 28 \\
$13-60$ & 33 & 90 \\
$61-108$ & 13 & 13 \\
$109-156$ & 9 & 4 \\
$\geq 157$ & 2 & 3 \\
\hline
\end{tabular}

\section{DISCUSSION}

Previous study show that the stress is the experience of perceived threat such as real or imagined to one's mental as well as spiritual well-being, resulting from the series of physiological responses [1]. Teacher stress is the experience of three emotions such as tension, anger and depression. Stress is not only harmful for the teachers but also for the teaching environment. In the present scenario, teachers have a lot of stress during the pandemic [3].

In response to the questionnaire, the associated range of it, when comparing the mean of responses for all 36 questions per individual, maximum individuals were found to be under the range of 2.1-3 and 3.1-4 (45\%) followed by individuals in the range of 1.0-2(6\%). The least number of responses were in the range of $4.1-5(4 \%)$.

Since the mean was calculated of all the 36 responses on the Likert 5 point scale of each individual, we can say that the maximum number of participants opted for rare, sometimes and often experienced stress in most of the questions. This was followed by few individuals who opted for never or rare experience of stress for most of the questions. Very few participants opted for always experienced stress. Hence one can say that maximum of the participants experienced moderate levels of stress and very few experienced severe levels of stress. 35 question were marked as sometimes experience stress by majority of participants out of 36 and 1 question were marked as a rare.

We compared the stress gender wise; the male response is 60 and the female response is 128 and the $t$ test was applied that was 0.52 which was not significant for the study, but according to a previous study by Ana SLIŠKOVIÆE1 and Darja MASLIÆE SERŠI/E (2011) shows that most university teachers have to cope with excessive workload. Women were reported to have higher exposure to stressors at work, to workload in particular teachers in middle positions (assistant professors and associate professors) reported the highest exposure to stressors, while full professors the lowest [12].

Present study shows that there is job stress in physiotherapy teachers, half of sample suffered from the rare and sometimes according to the 5-point Likert scale. There is no significant difference in male and female teachers, also there is no significant difference noted in the experience wise stress in teachers. Previous study by Ine Carmona Barrientos1, Francisco J. Gala León (2017) shows that $A$ high prevalence of occupational stress was detected among physiotherapists in Cadiz (Spain), as more than half of the sample suffered from a moderate to high level of occupational stress. Occupational stress was higher in females and professionals with temporary contracts. There was also a relationship between stress and workers with over 10 years of experience [12].

Accurate assessment could not be evaluated as the teachers filled the forms in accordance to their schedule, not as per the stress levels they experienced. This also adds limitations to the present study. As the forms were circulated on a larger basis, through all social 
platforms, responses received from male participants were less in comparison to female participants. Hence the study could not comment on significance for gender differentiation. also, the study excluded physiotherapy teachers who were taking psychotherapy.

\section{CONCLUSION}

After the application of Teacher Stress Inventory- Revised Scale amongst Indian physiotherapist teachers, this study concluded that on an average, the teachers experience stress sometimes amid COVID-19 Pandemic. Although there wasn't any significant gender wise difference. Also, the experience of the individuals mattered negligibly in this study.

\section{ACKNOWLEDGEMENTS}

It is indeed my privilege to express my sincere gratitude to Dr. Neeraj Kumar for his valuable advice and permitting me to carry out the project in this institution. Also, for encouraging me with his kind words throughout the project and providing me with material and links that I could not possibly have discovered on my own.

\section{Conflicts of interest: None}

\section{REFERENCES}

[1]. Seaward BL. Managing stress. Jones \& Bartlett Learning; 2017 Jul 24.

[2]. Swati Bhagat. Alternative therapies. 2004 Page number 87

[3]. Rosenberg, T. Teacher Stress: An Assessment of Teachers' Need for and Receptiveness towards a Stress Reduction Program within one Rural School System. 2010. Corpus ID: 59383218.

[4]. Folkman S. The case for positive emotions in the stress process. Anxiety, stress, and coping. 2008 Jan 1;21(1):3-14.
[5]. Harlow P. Stress, coping, job satisfaction, and experience in teachers (Doctoral dissertation), MSVU Thesis 2010.

[6]. Burks N, Martin B. Everyday problems and life change events: Ongoing versus acute sources of stress. Journal of Human Stress. 1985 Mar 1;11(1):27-35.

[7]. Rizwana Rafiq, Parvaiz Shah, Teacher's role and stress relationship: Review, International Journal of Human Resource \& Industrial Research 2015;2(3):08-17.

[8]. Laxman Singh \& Dr. Mohd Shakir, Teacher Education: Issues and Concerns in Current Scenario, IJRAR May 2019;6:2.

[9]. Allen R, Jerrim J, Simms S. How did the early stages of the COVID-19 pandemic affect teachers wellbeing? Centre for Education Policy and Equalising Opportunities (CEPEO) Working Paper. 2020 Sep;20-15.

[10]. Klapproth F, Federkeil L, Heinschke F, Jungmann T. Teachers' experiences of stress and their coping strategies during COVID-19 induced distance teaching. Journal of Pedagogical Research. 2020;4(4):444-52. https://doi.org/10.33902/ JPR.2020062805

[11]. Sliskovic A, Sersic DM. Work stress among university teachers: Gender and position differences. Arhiv Za Higijenu Rada I Toksikologiju. 2011 Oct 1;62(4):299.

[12]. Bane JV, Aurangabadkar S, Karajgi A. Physical and Self-Perceived Occupational Stress Associated with Work from Home Situation in Teachers during the COVID-19 Pandemic. International Journal of Health Sciences and Research 2021;11(2):117-124.

How to cite this article:
Ratnaprabha Chudiwal, Neeraj Kumar. Job stress in Physiotherapy Teachers
during COVID-19 Pandemic: A survey. Int J Physiother Res 2021;9(4):3895-
3899. DOI: 10.16965/ijpr.2021.139 